\title{
Technical Assistance for Primary Care Practice Transformation: Free Help to Perform Unpaid Labor?
}

\author{
Lawrence P. Casalino, MD, PbD \\ Department of Healthcare Policy and Research, Weill Cornell Medicine/New York-Presbyterian Hospital, New York, New York
}

Ann Fam Med 2018;16(Suppl 1):S12-S15. https://doi.org/10.1370/afm.2226.

$\mathrm{T}$ his issue of the Annals of Family Medicine includes multiple articles reporting early information from the implementation of the US Agency for Healthcare Research and Quality (AHRQ) initiative EvidenceNOW: Advancing Heart Health in Primary care. This $\$ 112$ million initiative-one of the largest in AHRQ's history-funds 7 cross-organizational collaboratives to assist 1,500 small (fewer than 10 clinicians) primary care practices to improve their care for cardiovascular disease. Meyers et al ${ }^{1}$ provide thoughtful explanations of the ways in which AHRQ designed EvidenceNOW to navigate the trade-offs between implementation (including permitting flexibility and local adaptation) and rigorous evaluation. ${ }^{1}$

EvidenceNOW raises many important questionsI will focus on 3. Why should anyone care about small primary care practices? Why should small primary care practices transform the ways they provide care? What might it take for small primary care practices to transform?

There are at least 3 reasons to care about small primary care practices. First, though the number has been declining, $51 \%$ of primary care physicians still work in practices of 5 or fewer physicians. ${ }^{2}$ Second, some physicians and patients prefer the small practice setting. ${ }^{3}$ Third, small practices may have some advantages

Conflict of interest: Casalino served as a part-time senior advisor to the Director of the US Agency for Healthcare Research and Quality (AHRQ) from 2014 to 2016 (not on the EvidenceNOW project.), consults with Mathematica Policy Research Institute on the evaluation of the Comprebensive Primary Care Plus initiative, has served on the Board of Trustees of the American Medical Group Association Foundation, and serves on an Advisory Committee on Professional Satisfaction and Practice Sustainability for the American Medical Association.

\section{CORRESPONDING AUTHOR}

Lawrence P. Casalino, MD, PhD

Department of Healthcare Policy and Research

Weill Cornell Medicine New York-Presbyterian Hospital

402 E. 67th St, Room LA 217

New York, NY 10065-6304

Lac2021@med.cornell.edu over large organizations: patients' access to care may be easier, ${ }^{4}$ and the human scale and potentially close relations among patients, physicians, and staff may lead to high-value care. ${ }^{5}$ There are not many studies comparing small practices with large ones; the data that do exist suggest that large organizations with many clinicians use more systematic processes to improve care and may score better on process measures, but they do not necessarily score better on outcome measures of care, such as total spending or ambulatory care-sensitive admissions. ${ }^{6-10}$

Large medical organizations have the resources and scale to invest in systematic processes to improve the care they provide, including employing skilled leaders whose full-time job is quality improvement. Large organizations, however, may also suffer from diseconomies of scale, such as excessive bureaucratization. Two anecdotes-one of bureaucracy, the second of human scale-may suggest some of the advantages of small practices.

Recently, a physician friend of mine developed an irregular heartbeat. Within 90 minutes, he was able to see his primary care physician, who practices in a large group at a well-known academic medical center (not the center where I work). The physician explained that the primary care practice was not permitted to have electrocardiogram (ECG) machines and that my friend would have to have his ECG at the ECG clinic-a 20 -minute walk away - where it would be read by a cardiologist. Heart pounding, my friend walked there and was told that it would be a 60 -minute wait to have his ECG, or he could make an appointment to have it done the next morning. An hour later, when he had the ECG, he was in normal sinus rhythm, so the opportunity to diagnose the arrhythmia was lost.

A second anecdote: during my 20 years in an independent, 9-physician, primary care practice, I had a total of 3 medical assistants (sequentially). We knew and trusted each other, and our regular patients knew and trusted us as a unit. It would often happen that my medical assistant would stop me as I hastened 
between examination rooms, saying, "Larry, Mr. just called." Before I could react, she would hasten to say, "I know, I know, he calls almost every day. But today I just don't like the way he sounds. I think there's something wrong ${ }_{i}$ I think we ought to get him right in." I would say, "OK," and we would intervene in time to prevent a serious event.

Why should small primary care practices transform the ways in which they provide care? From policy makers' perspectives, practices ought to transform themselves into patient-centered medical homes. ${ }^{11}$ They should use systematic processes to improve care, such as the use of disease registries, written care plans for patients, nurse care managers for patients with chronic diseases, clinical decision support, measurements of a practice's quality performance with feedback to physicians and staff, and such methods as plan-do-study-act to identify problems and test solutions. The evidence is mixed on whether these processes, individually or collectively, improve the quality of care, ${ }^{12-14}$ but many policy makers and physicians reasonably believe that, with time, the use of such processes will in fact improve quality and reduce unnecessary costs of care. ${ }^{15}$ It is also hoped that transforming practices will lead to less chaotic, more satisfying experiences at work for physicians and practice staff. ${ }^{16}$

Physicians and staff, however, may or may not believe that transforming their practice will improve their work lives, help them take better care of their patients, and lead to a positive return on investmentor at least not be a financial negative for the practice. When they do believe, this belief alone may not be enough for them to be enthusiastic about expending time and energy and making financial investments to change their familiar patterns of work and deal with unknown disruptions that may occur. In fact, some efforts to transform primary care practices have led to increased physician and staff burnout. ${ }^{17}$

Physicians and staff in small primary care practices feel that they have more than they can do to care for their patients, to deal with the regulatory and reporting demands of value-based purchasing programs, to obtain reimbursement from payers for the care they provide, and to run their business. At the end of a long, pressured day of seeing patients and dealing with the electronic health record, practice leaders may have little time or energy left for thinking about practice transformation, much less making it happen, even if they believe thatsomeday-transformation would be better for them and for their patients. Because most or all reimbursement for primary care practices comes from claims for providing face-to-face patient care, practices may be reluctant to pay any physician or staff member to take time away from care to work on practice transformation.
Early findings from EvidenceNOW provide some support for these hypotheses. For example, Fagnan et al ${ }^{18}$ found that it cost nearly $\$ 2.7$ million to recruit 484 practices into EvidenceNOW. Only 1 in 20 practices that did not have a previous relationship with the recruiters, or a "warm handoff" from another practice, agreed to participate, despite multiple recruitment attempts using a variety of recruiters and methods of contact.

Many practices that did participate paid little attention to the EvidenceNOW facilitators who tried to provide free assistance to the practices. For example, $\mathrm{McHugh}$ et $\mathrm{a}^{19}$ found that though practice leaders described their experience with EvidenceNOW in positive terms, they often described the initiative as a relatively low priority. EvidenceNOW facilitators frequently reported difficulty gaining attention from practice leaders and staff. Some practice leaders limited their time with the facilitator to 15 minutes per month. Practice leaders typically reported engaging in fewer than 5 of the 35 quality improvement strategies offered by the facilitators. Practice facilitators reported that the easiest interventions to implement were those-such as electronic health record documentation support - that did not alter care practices.

EvidenceNOW offers free assistance, but making use of the assistance requires unpaid labor from physicians and staff. Unlike payers such as Medicare and health insurance companies, AHRQ cannot provide funding to practices to support their quality improvement efforts. Small primary care practices have no organizational slack to put unpaid effort into activities that are not likely to have an immediate payoff. An offer to give free swimming lessons to a drowning person-no matter how well-intentioned-may not be enthusiastically received. Just get me out of the water!

It is too soon to know whether EvidenceNOW will result in improved patient care in participating practices. At the very least, much will be learned about efforts to implement assistance to practices. But if free technical assistance alone is not enough, what else might it take, in addition to technical assistance, for small primary care practices to transform? Four approaches might help.

First, practices need some slack-they are unlikely to transform if physicians and staff are struggling every moment to keep their heads above water. Innovative companies in other industries have realized that trying to squeeze maximum task efficiency out of workers at every moment leads to fewer good ideas and lower productivity. ${ }^{20,21}$ Slack could be provided by making electronic health records less time-consuming to use, by reducing reporting requirements for practices (for example, in value-based purchasing programs such as the Centers for Medicare \& Medicaid Services [CMS] 
merit-based incentive payment system [MIPS]), and by paying higher rates for primary care services, which would reduce the pressure to see as many patients as possible as rapidly as possible. Primary care is generally thought to be essential to improving the health of a population while controlling spending on care, yet commercial insurers in the United States spend only $8 \%$ of the amount they pay for health care services on primary care. ${ }^{22}$ The Oregon legislature recently passed a bill mandating that commercial insurers, Medicaidcoordinated care organizations, and health plans serving public employees have a minimum primary care spending rate of $12 \%$, effective by $2023 .{ }^{23}$

Second, primary care practices could receive part of their reimbursement prospectively rather than through fee-for-service payments. For example, they could receive prospective monthly, risk-adjusted, per-patient payments to fund their implementation of systematic processes to improve the care that practices provide to patients. The CMS Comprehensive Primary Care Plus $(\mathrm{CPC}+)$ initiative is using such payments; similar payments are proposed in the American Academy of Family Physicians (AAFP) Alternative Payment model ${ }_{1}^{24}$ which was evaluated favorably by the Physician-Focused Payment Model Technical Advisory Committee. ${ }^{25}$

Third, small primary care practices could be financially rewarded for good performance on measures of quality, cost, and patient experience. This solution, I believe, is the most problematic, though to date it has been the most commonly used. At present, payer program rewards to small primary care practices (such as MIPS) are usually relatively spare, and the time between the practice investing resources in improving quality and the reward may be 1 to 2 years. In addition, the performance reporting required may be burdensome for practices, ${ }^{26}$ and the performance measures may not be strong, in part because small practices do not have a sufficient number of patients to measure quality reliably for such "strong" outcome measures as ambulatory care-sensitive admissions or even for some process measures of care ${ }^{27}$ One possibility, recently discussed favorably by the Medicare Payment Advisory Commission (MedPAC), would be for small primary care practices to band together into informal groups for purposes of measurement and reward. ${ }^{28}$

Fourth, small primary care practices could share resources for improving care. ${ }^{29}$ For example, a small practice may not have the number of seriously ill patients to support employing a nurse care manager to assist these patients. But multiple practices could share a care manager. Shared care management could be a collateral benefit of the informal groups proposed by MedPAC, in which practices within such a group could agree to share resources to improve care.
The second and third suggestions above are similar to those proposed in the AAFP Alternative Payment Model and to payment mechanisms actually being used in the CPC+ initiative, especially track 2 of this initiative. The Comprehensive Primary Care Initiative, the predecessor to $\mathrm{CPC}+$, obtained promising results on cost and quality of care. ${ }^{30}$

As the articles in this issue of the Annals suggest, EvidenceNOW is already providing rich information about how to implement technical assistance to small practices. EvidenceNOW and the CMS Innovation Center's $\$ 700$ million Transforming Clinical Practice Initiative are bold efforts to address important questions, such as, for example, which forms of technical assistance to practices are most effective? Perhaps the most fundamental questions for which these 2 initiatives will provide evidence are (1) will free technical assistance, along with the value-based purchasing initiatives that currently exist, lead to transformation in small practices; and (2) will this transformation lead to better care for patients?

Both initiatives hypothesize, in effect, that if free technical assistance is provided, practices will supply free labor to transform. This hypothesis may overestimate the extent to which current value-based purchasing programs are perceived by small practices as likely to reward them adequately for their efforts to provide care differently. The rewards offered by most value-based purchasing programs may be perceived as too difficult to understand, too uncertain, too small, too challenging to achieve, too far away in time, and requiring too much effort from the practice to report performance. If payers want to transform the US health care system, they may need to make larger up-front investments-not just in technical assistance, but in providing funds that reward practices for implementing systematic processes to improve their quality of care. But this is merely a hypothesis. EvidenceNOW will provide evidence to help answer this question.

To read or post commentaries in response to this article, see it online at http://www.AnnFamMed.org/content/16/Suppl_1/S12.

Key words: physician practices; medical groups; technical assistance; quality improvement

Submitted February 16, 2018; accepted February 20, 2018.

Funding support: Publication of this article was supported by the Agency for Healthcare Research and Quality (AHRQ) through contract No. HHSA290201200019I. This work was supported in part by the Physicians Foundation Center for the Study of Physician Practice and Leadership at Weill Cornell Medical College, New York, NY.

Disclaimer: This work represents the opinions of the author and should not be interpreted as official positions of the Agency for Healthcare Research and Quality or the US Department of Health and Human Ser- 
vices. The views in this article are the author's views, and do not necessarily represent the viewpoint of the Physicians Foundation.

\section{References}

1. Meyers D, Miller T, Genero J, et al. EvidenceNOW: Balancing primary care implementation and implementation research. Ann Fam Med. 2018;16(Suppl 1):S5-S11.

2. Liaw WR, Jetty A, Petterson SM, Peterson LE, Bazemore AW. Solo and small practices: a vital, diverse part of primary care. Ann Fam Med. 2016;14(1):8-15.

3. van den Hombergh $P$, Engels $Y$, van den Hoogen $H$, van Doremalen J, van den Bosch W, Grol R. Saying 'goodbye' to single-handed practices; what do patients and staff lose or gain? Fam Pract. 2005; 22(1):20-27.

4. Kontopantelis E, Roland M, Reeves D. Patient experience of access to primary care: identification of predictors in a national patient survey. BMC Fam Pract. 2010;11:61

5. Aronson L. A tale of two doctors - structural inequalities and the culture of medicine. N Engl J Med. 2017;376(24):2390-2393.

6. Casalino LP, Pesko MF, Ryan AM, et al. Small primary care physician practices have low rates of preventable hospital admissions. Health Aff (Millwood). 2014;33(9):1680-1688.

7. Rittenhouse DR, Casalino LP, Shortell SM, et al. Small and mediumsize physician practices use few patient-centered medical home processes. Health Aff (Millwood). 2011;30(8):1575-1584.

8. MCWilliams JM, Chernew ME, Zaslavsky AM, Hamed P, Landon BE. Delivery system integration and health care spending and quality for Medicare beneficiaries. JAMA Intern Med. 2013;173(15):1447-1456.

9. Wiley JA, Rittenhouse DR, Shortell SM, et al. Managing chronic illness: physician practices increased the use of care management and medical home processes. Health Aff (Millwood). 2015;34(1):78-86.

10. Weeks WB, Gottlieb DJ, Nyweide DE, et al. Higher health care quality and bigger savings found at large multispecialty medical groups. Health Aff (Millwood). 2010;29(5):991-997.

11. Ayanian JZ, Hamel MB. Transforming primary care-we get what we pay for. N Engl J Med. 2016;374(24):2390-2392.

12. Sinaiko $A D$, Landrum MB, Meyers $D$ J, et al. Synthesis of research on patient-centered medical homes brings systematic differences into relief. Health Aff (Millwood). 2017;36(3):500-508.

13. Friedberg MW, Rosenthal MB, Werner RM, Volpp KG, Schneider EC. Effects of a medical home and shared savings intervention on quality and utilization of care. JAMA Intern Med. 2015;175(8):1362-1368.

14. Mendelson A, Kondo K, Damberg C, et al. The effects of pay-forperformance programs on health, health care use, and processes of care: A systematic review. Ann Intern Med. 2017;166(5):341-353.

15. Jackson GL, Williams JW Jr. Does PCMH "work"?-the need to use implementation science to make sense of conflicting results. JAMA Intern Med. 2015;175(8):1369-1370.

16. Shipman SA, Sinsky CA. Expanding primary care capacity by reducing waste and improving the efficiency of care. Health Aff (Millwood). 2013;32(11):1990-1997.
17. Meredith LS, Schmidt Hackbarth N, Darling J, et al. Emotional exhaustion in primary care during early implementation of the VA's medical home transformation: Patient-aligned Care Team (PACT). Med Care. 2015;53(3):253-260.

18. Fagnan $\mathrm{LJ}$, Walunas $\mathrm{TL}$, Parchman $\mathrm{ML}$, et al. Engaging primary care practices in studies of improvement: did you budget enough for practice recruitment? Ann Fam Med. 2018;16(Suppl 1):S72-S79.

19. McHugh M, Brown T, Liss DT, Walunas TL, Persell SD. Practice facilitators' and leaders' perspectives on a facilitated quality improvement program. Ann Fam Med. 2018;16(Suppl 1):S56-S71.

20. Asch DA, Terwiesch C, Mahoney KB, Rosin R. Insourcing health care innovation. N Engl J Med. 2014;370(19):1775-1777.

21. Rosin R, Fieldston E, Asch DA. Seeing clinician slack as a strategic investment. Health Affairs blog. https://www.healthaffairs.org/do/ 10.1377/hblog20140801.040304/full. Published Feb 15, 2014.

22. Schneider EC, Squires D. From last to first - could the U.S. health care system become the best in the world? N Engl J Med. 2017; 377(10):901-904.

23. Koller $C F$, Khullar D. Primary care spending rate - a lever for encouraging investment in primary care. N Engl J Med. 2017; 377(18):1709-1711

24. American Academy of Family Physicians. Advanced primary care: a foundational alternative payment model (APC-APM) for delivering patient-centered, longitudinal, and coordinated care. https:// www.aafp.org/dam/AAFP/documents/advocacy/payment/apms/ PR-PTAC-APC-APM-41417.pdf. Published Apr 14, 2017. Accessed Mar 25, 2018.

25. Physician Focused Payment Model Technical Advisory Committee. Preliminary review team findings: advanced primary care: a foundational alternative payment model (APC-APM) for delivering patientcentered, longitudinal, and coordinated care. https://aspe.hhs.gov/ system/files/pdf/255736/12-19Presentations.pdf. Published Dec 19, 2017. Accessed Feb 15, 2018.

26. Casalino LP. The Medicare access and CHIP reauthorization act and the corporate transformation of American medicine. Health Aff (Millwood). 2017;36(5):865-869.

27. Nyweide DJ, Weeks WB, Gottlieb DJ, Casalino LP, Fisher ES. Relationship of primary care physicians' patient caseload with measurement of quality and cost performance. JAMA. 2009;302(22): 2444-2450.

28. Dickson V. MedPAC votes 14-2 to junk MIPS, providers angered. Modern Healthcare. http://www.modernhealthcare.com/article/2018 0111/NEWS/180119963. Published Jan 11, 2018.

29. Khullar D, Burke GC, Casalino LP. Can small physician practices survive?: Sharing services as a path to viability. JAMA. https://jamanetwork.com/journals/jama/fullarticle/2673278. Published Feb 19, 2018.

30. Dale SB, Ghosh A, Peikes DN, et al. Two-year costs and quality in the comprehensive primary care initiative. N Engl J Med. 2016; 374(24):2345-2356. 